\title{
Mathematical Model and Analytical Solution for Groundwater Seepage in Confined Aquifer Subjected to Well Pumping without Penetrating Overlying Aquiclude
}

\author{
Yulin Wang ${ }^{1,4}$, Kanghe $\mathrm{Xie}^{2}$ and Xiaohua Zhao ${ }^{3,4}$ \\ ${ }^{1}$ Department of Civil Engineering and Architecture, Wuyi University, Wuyishan 354300, China \\ ${ }^{2}$ MOE Key Laboratory of Soft Soils and Geoenvironmental Engineering, Zhejiang University, Hangzhou 310027, China \\ ${ }^{3}$ Department of Civil and Environmental Engineering, Shantou University, Shantou 515063, China \\ ${ }^{4}$ Key Laboratory of Structure and Wind Tunnel of Guangdong Higher Education Institutes, Shantou 515063, China
}

\begin{abstract}
Groundwater in confined aquifer was pumped at constant rate through base plate of a vertical well without penetrating overlying aquiclude, a mathematical model for seepage in confined aquifer was developed, and by technique of integral transforms of Hankel Transformation and Laplace Transformation respectively, the analytical solution was attained. By a numerical example, the seepage of groundwaAter was analyzed, and some conclusions were derived: (1) The drawdown of hydraulic head in the confined aquifer decreases with the depth and with the distance away from pumping well; (2) The effect of base plate size of pumping well on the drawdown of hydraulic head is finite and mainly converges on the vicinity of base plate of pumping well; (3) The resistance coefficient of leakage $B$ remarkably affects the distribution of drawdown, and the smaller $B$ leads to more water leaking from aquiclude into the confined aquifer to reduce amplitude of drawdown in confined aquifer due to pumping
\end{abstract}

Keywords-groundwater; confined aquifer; anlytical solution; nonpenetrating well; integral transfomation

\section{INTRODUCTION}

To analyze vertical well flow in confined aquifer, there are two kinds of mathematical models for simulation of groundwater: one model is fully penetrating well[1-6], in which pumping well fully penetrates the confined aquifer, and the other is partially penetrating well[7-9], in which the pumping well partially penetrates the confined aquifer. As it is well known, there is a overlying impermeable layer or aquiclude above the confined aquifer, and the pumping well should penetrates the overlying aquiclude in the above mentioned models[10-14]. However, in geotechnical engineering or hydraulic engineering, some vertical wells don't penetrating the overlying aquiclude, and these wells pump the water that comes from confined aquifers. For example, in foundation excavation engineering, pumping wells are applied to lower the level of water below the base plate of foundation pit, and pumping wells sometimes will not penetrate the overlying aquiclude to dewater, when confined aquifer is far below the base plate of foundation pit but the hydraulic head is above base plate of foundation pit and threaten the stability during excavation. The existing mathematical models are not developed to study the seepage of groundwater for such a kind of problem. Therefore, it is necessary to establish a new mathematical model to solve the problem.

In this paper, the mathematical model of seepage flow for confined aquifer subjected to a constant pumping rate through vertical well without penetrating overlying aquiclude was presented, and by using Hankel Transformation and Laplace Transformation, analytical solution was attained. According to the derived solution, a numerical example was used to analyze the groundwater seepage in confined aquifer and the relative influence factors.

\section{MATHEMATICAL MODEL}

\section{A. Basic Assumption}

Figure I illustrates the conceptual model of seepage flow of groundwater, in which the pumping well doesn't penetrate the overlying aquiclude above the confined aquifer and the groundwater was pumped with a constant pumping rate $Q$. To derive the corresponding mathematical model, some basic assumptions are proposed: (1) the material in confined aquifer is anisotropic and the flux from base plate of pumping well is uniform; (2) M.s.Hantush assumptions are introduced here, that is vertical leakage from overlying aquiclude is in proportion to hydraulic head in the confined aquifer; (3) Leakage recharge from overlying aquiclude is deemed as source and sink in the mathematical model and the top of confined aquifer is regarded as impermeable boundary; (4) The lateral boundary condition is a contant hydraulic head. 


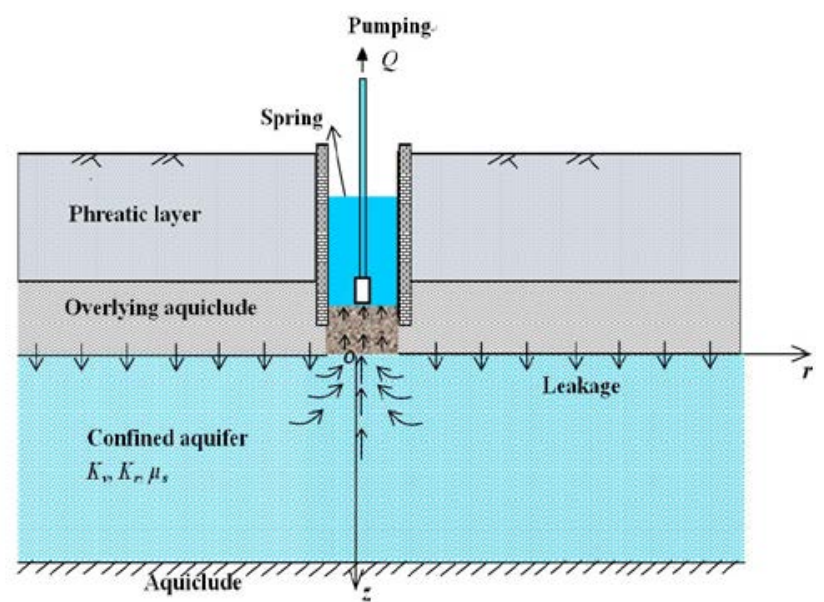

FIGURE I.CONCEPTUAL MODEL FOR SEEPAGE OF GROUNDWATER OF CONFINED AQUIFER DUE TO CONSTANT RATE PUMPING: PUMPING WELL DOESN'T PENETRATE THE OVERLYING AQUICLUDE.

\section{B. Governing Equations and Conditions for Seepage Field of} Groundwater

The cylindral coordinates is established as shown in the conceptual model in Figure I . According to the conceptual model and basic assumptions, the governing equation for three dimensional seepage flow is derived as below:

$$
K_{r}\left(\frac{\partial^{2} s}{\partial r^{2}}+\frac{1}{r} \frac{\partial s}{\partial r}\right)+K_{v} \frac{\partial^{2} s}{\partial z^{2}}-\frac{K^{\prime} s}{b b^{\prime}}=\mu_{s} \frac{\partial s}{\partial t}
$$

The corresponding boundary conditions and initial condition is listed as:

(a) The top boundary condition for seepage flow of confined aquifer: $\left\{\begin{array}{l}\left.\frac{\partial s}{\partial z}\right|_{z=0}=0, r>r_{0} \\ \left.\frac{\partial s}{\partial z}\right|_{z=0}=\frac{Q}{K_{v}{ }^{\prime} \pi r_{0}{ }^{2}}, r \leq r_{0}\end{array} ;\right.$ (b) Base plate boundary condition: $\left.\frac{\partial s}{\partial z}\right|_{z=b}=0 ;$ (c) Initial condition: $\left.S\right|_{t=0}=0$

Where $s$ is drawdown of hydraulic head in confined aquifer; $r$ and $z$ are radial coordinate variable and vertical coordinate variable; $t$ is time variable; $Q$ is pumping rate of groundwater; $K_{r}$ and $K_{v}$ are radial permeability and vertical permeability of confined aquifer respectively; $K{ }^{\prime}$ and $K_{v}{ }^{\prime}$ are radial permeability and vertical permeability of overlying aquiclude respectively; $\mu_{s}$ is specific elastic storage coefficient of confined aquifer; $b$ and $b$ are thickness of confined aquifer and overlying aquiclude respectively; $r_{0}$ is radius of permeable base plate of well.

\section{Laplace - Hankel Integral Transform Form of Mathematical Model}

To transfer the nonhomogeneous equation to be a homogeneous equation, let $z^{*}=\vartheta z$ and $\vartheta=\sqrt{K_{r} / K_{v}}$ in (1), and at the same time Laplace Transformation and Hankel transformation were applied to (1). In consequence, equation (1) in physical domain was changed into the equation in HankelLaplace domain as below:

$$
\frac{d^{2} \hat{\hat{s}}}{d z^{* 2}}-\left(\xi^{2}+\frac{1}{B^{2}}+\frac{p}{a_{r}}\right) \tilde{\hat{s}}=0
$$

Where $\tilde{\hat{S}}$ is drawdown of hydraulic head in Laplace-Hankel domain; $B=\sqrt{K_{r} b^{\prime} b / K^{\prime}}$ is resistance coefficient of Leakage; $a_{r}=T_{r} / \mu_{e}$ is radial conductivity coefficient of confined aquifer; $T_{r}=K_{r} b$ is radial transmissivity of confined aquifer; $\mu_{e}$ is elastic storage coefficient of confined aquifer; $\xi$ and $\mathrm{p}$ are variables in Hankel domain and Laplace domain respectively.

After Laplace transformation and Hankel transformation in order of priority, both of the upper boundary condition and lower boundary condition were changed to Laplace-Hankel domain: ( I ) upper boundary condition in Laplace-Hankel domain: $\frac{d \tilde{s}}{d z^{*}}=\frac{Q}{\vartheta K_{v}{ }^{\prime} \pi r_{0} p \xi} J_{1}\left(\xi r_{0}\right)$; ( II ) lower boundary condition in Laplace and Hankel domain: $\left.\frac{d \tilde{s}}{d z^{*}}\right|_{z^{*}=\vartheta z}=0$.

Where $J_{1}\left(\xi r_{0}\right)$ is first order Bessel Function.

\section{ANALYTICAL SOLUTION}

\section{A. Solution of Hankel-Laplace Domain for Hydraulic Drawdown}

Equation (2) is ordinary differential equation, and the general solution is attained as:

$$
\tilde{\hat{S}}=C e^{-\sqrt{\xi^{2}+\frac{1}{B^{2}}+\frac{p}{a_{r}}} z^{*}}+D e^{\sqrt{\xi^{2}+\frac{1}{B^{2}}+\frac{p}{a_{r}}} z^{*}}
$$

Where C and D are undetermined constants.

By using boundary conditions ( I )and ( II ), constants C and $\mathrm{D}$ could be attained as following:

$$
\left\{\begin{array}{c}
C=-\frac{Q \gamma_{w} J_{1}\left(\xi r_{0}\right)}{K_{v}^{\prime} \pi r_{0} \vartheta \xi p \sqrt{\xi^{2}+\frac{1}{B^{2}}+\frac{p}{a_{r}}}} \frac{e^{2 \vartheta b \sqrt{\xi^{2}+\frac{1}{B^{2}}+\frac{p}{a_{r}}}}}{\left(e^{2 \vartheta b \sqrt{\xi^{2}+\frac{1}{B^{2}}+\frac{p}{a_{r}}}}-1\right)} \\
D=-\frac{1}{K_{v}^{\prime} \pi r_{0} \vartheta \xi p \sqrt{\xi^{2}+\frac{1}{B^{2}}+\frac{p}{a_{r}}}}\left(e^{\left.2 \vartheta b \sqrt{\xi^{2}+\frac{1}{B^{2}+\frac{p}{a_{r}}}}-1\right)}\right)
\end{array}\right.
$$


By substituting determined constants C and D into (3), the solution in Laplace-Hankel domain was derived:

$$
\tilde{s}=-\frac{Q J_{1}\left(\xi r_{0}\right)}{K_{v}^{\prime} \pi r_{0} \vartheta \xi} \frac{1}{p} \frac{C h\left[\vartheta(b-z) \sqrt{\xi^{2}+\frac{1}{B^{2}}+\frac{p}{a_{r}}}\right]}{\sqrt{\xi^{2}+\frac{1}{B^{2}}+\frac{p}{a_{r}}} \operatorname{Sh}\left(\vartheta b \sqrt{\xi^{2}+\frac{1}{B^{2}}+\frac{p}{a_{r}}}\right)}
$$

\section{B. Solution of Physical Domain}

Inverse transformation of Hankel transformation and Laplace transformation were applied to (5) respectively, and solution in physical domain was attained as below:

$$
\begin{aligned}
& s=-\frac{2 Q}{K_{v} \pi r_{0} L^{2} b \vartheta^{2}} \sum_{m=1}^{\infty} \frac{J_{1}\left(\xi_{m} r_{0}\right) J_{0}\left(\xi_{m} r\right)}{\xi_{m} J_{1}^{2}\left(\xi_{m} L\right)}\left\{\frac{1}{\xi_{m}{ }^{2}+\frac{1}{B^{2}}}\left(1-e^{-\left(\xi_{m}^{2}+\frac{1}{B^{2}}\right) a_{r} t}\right)\right. \\
& \left.+2 \sum_{n=1}^{\infty}(-1)^{n} \frac{1}{\xi_{m}^{2}+\frac{1}{B^{2}}+\frac{n^{2} \pi^{2}}{\vartheta^{2} b^{2}}} \cos \left[\frac{n \pi(b-z)}{b}\right] \cdot\left[1-e^{-\left(\frac{n^{2} \pi^{2}}{g^{2} b^{2}} \xi_{m}^{2}+\frac{1}{B^{2}}\right) a_{r}}\right]\right\}
\end{aligned}
$$

\section{ANAYLSIS OF HydRAULIC DRAWDOWN OF CONFINED AQUIFER}

\section{A. Vertical Distribution of Drawdown of Hydraulic Head}

Figure II shows the distribution of drawdown of hydraulic head along depth of confined aquifer. It can be seen that the drawdown of hydraulic head decreases with the depth in the confined aquifer and the vertical distribution of drawdown of hydraulic head is greatly affected by the distance away from pumping well. When $r=50 \mathrm{~m}$, the drawdown is $15 \mathrm{~m}$ at upper boundary and $11 \mathrm{~m}$ at lower boundary, while as for $r=100 \mathrm{~m}$, the distribution is much more uniform and the drawdown is $9.8 \mathrm{~m}$ at upper boundary and $9.5 \mathrm{~m}$ at lower boundary.

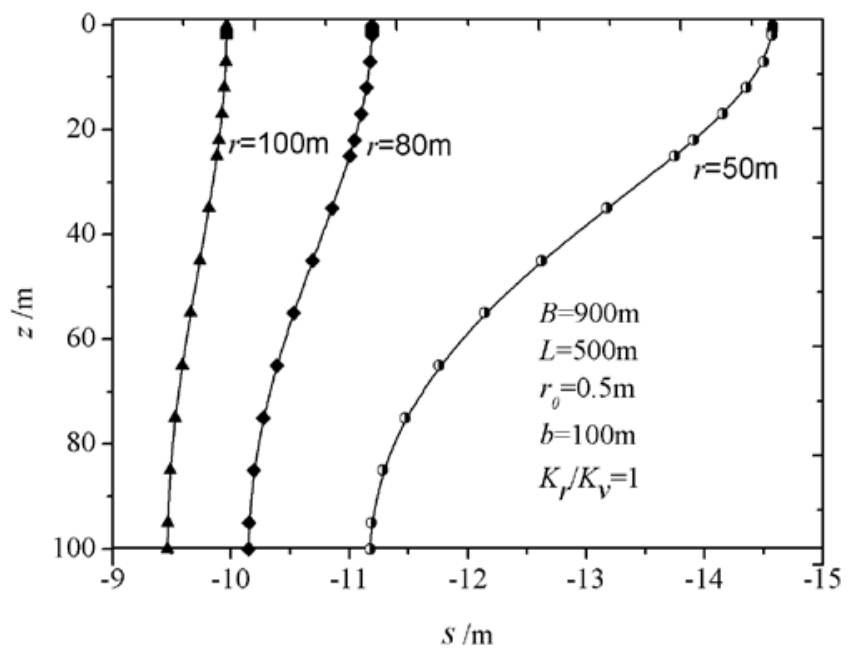

FIGURE II. DISTRIBUTION OF DRAWDOWN OF HYDRAULIC HEAD ALONG DEPTH OF CONFINED AQUIFER

\section{B. Effect of Base Plate Size of Pumping Well on Groundwater Seepage}

Figure III shows the radial distribution of drawdown of hydraulic head along the distance from pumping well with different base plate sizes of pumping well. It indicates that the drawdown of hydraulic head increases with decreasing distance from pumping well, which shape looks like "s", and the drawdown in the vicinity of the pumping well will be greatly affected by base plate size of pumping well but the effect attenuates with increasing distance away from pumping well. As the numerical example shown, the drawdown are $185 \mathrm{~m}$, $217 \mathrm{~m}, 229 \mathrm{~m}$ and $233 \mathrm{~m}$ for different base plate size of pumping well $r_{0}=2.0 \mathrm{~m}, 1.0,0.5$ and $0.1 \mathrm{~m}$ respectively, at location $r=0.1 \mathrm{~m}$. The difference affected by the base plate size becomes trivial for the distance $r$ greater than $2 \mathrm{~m}$. It means that the effect of base plate size of pumping well on the drawdown of hydraulic head is finite and mainly focuses on the vicinity of base plate of pumping well.

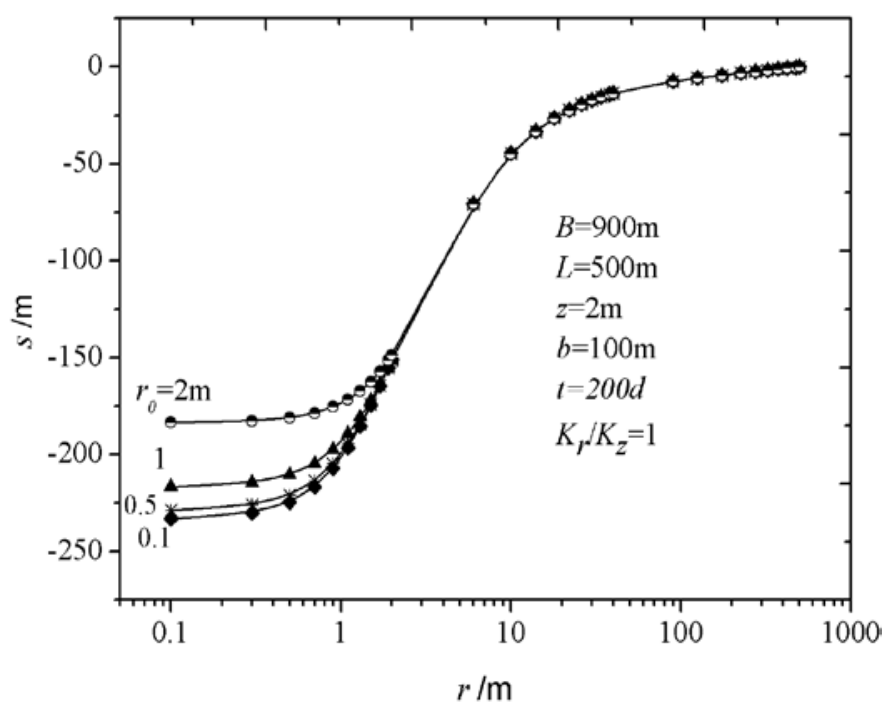

FIGURE III. $\quad$ EFFECT OF BASE PLATE SIZE OF PUMPING WELL ON THE DRAWDOWN OF HYDRAULIC HEAD

\section{Effect of Leakage from Aquiclude on Seepage of Groundwater}

Figure IV shows the effect of leakage of water from aquiclude on the seepage in confined aquifer. By comparing the curves for four $B=200 \mathrm{~m}, 300 \mathrm{~m}, 600 \mathrm{~m}$ and $1500 \mathrm{~min}$ Fig.4, it can be see that: (1) all curves have the same trend that hydraulic drawdown decreases with distance increase and is zero at the location $L=500 \mathrm{~m}$ for constant hydraulic head of boundary condition; (2) the resistance coefficient of leakage B remarkably affects the radial distribution of drawdown, and the smaller B will make the drawdown smaller, because smaller B means more water leakage from aquiclude into confined aquifer to reduce the water lost in confined aquifer due to pumping. 


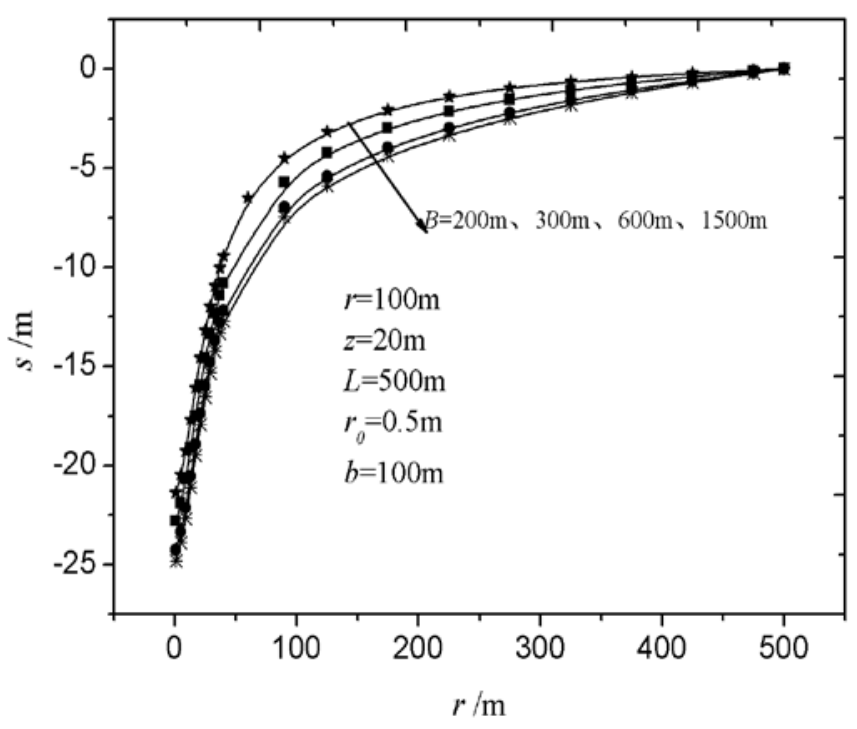

FIGURE IV. EFFECT OF LEAKAGE FROM AQUICLUDE ON THE DRAWDOWN OF HYDRAULIC HEAD IN CONFINED AQUIFER

\section{CONCLUSIONS}

The mathematical model of seepage flow for confined aquifer subjected to pumping well without penetrating into overlying aquiclude was developed, and by technique of integral transforms of Hankel Transformation and Laplace Transformation, analytical solution was derived. By analysis of a numerical example, conclusions were attained as following: (1) The drawdown of hydraulic head in the confined aquifer decreases with the depth and with the distance away from pumping well; (2) The effect of base plate size of pumping well on the drawdown of hydraulic head is finite and mainly converges on the vicinity of base plate of pumping well; (3) The resistance coefficient of leakage $B$ remarkably affects the distribution of drawdown, and the smaller B will make the hydraulic drawdown smaller for smaller B leads to more water leaking from aquiclude into the confined aquifer to reduce the water lost in confined aquifer due to pumping.

\section{ACKNOWLEDGMENT}

This research is supported by New Century Talent Plan in Colleges and Universities sponsored by Educational Department of Fujian Province (MinJiaoKe[2016]No.23); Educational Research Projects for Young Teachers(JZ16020); Young Doctor Team of Discipline (WuYuanZong[2017]No.66) supported by Wuyi University, and by Fund of Key Laboratory of Structure and Wind Tunnel of Guangdong Higher Education Institutes (Grant No.201401)

\section{REFERENCES}

[1] Bruce Hunt.Unsteady Stream Depletion when Pumping from Semiconfined Aquifer[J].Journal Of Hydrologic Engineering,2003,8 (1):12-19.

[2] Tomas Perina,Lee, Tien-Chang.General well function for pumping from a confined, leaky, or unconfined aquifer[J].Journal of Hydrology,2006,317 (3-4):239-260

[3] Zhang Wen, Huang, Guanhua,Zhan, Hongbin.An analytical solution for non-Darcian flow in a confined aquifer using the power law function[J].Advances In Water Resources,2008,31 (1):44-55.
[4] Wangang Chen, Yu Yang, Hansen Sun, Chengwei Zhang, Qin Wen,Yanyan Li.Solution and type curves for the seepage model of the water-bearing coalbed with leakage recharge[J].EARTH SCIENCES RESEARCH JOURNAL,2017,21 (1):17-21.

[5] Peter Dudfield,Woods, Andrew W.Early-time periodic injection and extraction in an inclined confined aquifer[J].J. Fluid Mech,2015,776:430-457.

[6] Chiu-Shia Fen,Yeh, Hund-Der.Effect of Well Radius on Drawdown Solutions Obtained with Laplace Transform and Green's Function[J].Water Resour Manage,2012,26:377-390.

[7] G. Cassiani, Kabala, Z.J.Jr., M.A. Medina.Flowing partially penetrating well: solution to a mixed-type boundary value problem[J].Advances In Water Resources, 1999,23:59-68.

[8] Y. C. Chang,Yeh, H. D.New solutions to the constant-head test performed at a partially penetrating well[J].Journal Of Hydrology,2009,369 (1-2):90-97.

[9] Gautam Barua,Bora, S.N.Hydraulics of a partially penetrating well with skin zone in a confined aquifer[J].Advances In Water Resources,2010,33:1575-1587.

[10] Zhang Wen, Zhan, Hong Bin, Huang, Guan Bua,Jin, Menggui.Constanthead test in a leaky aquifer with a finite-thickness skin[J].Journal of Hydrology,2011,399 (3):326-334.

[11] Hund Der Yeh,Chang, Ya Chi.Recent advances in modeling of well hydraulics[J].Advances in water resources,2013,51:27-51.

[12] Shaw Yang Yang, Yeh, Hund Der,Chiu, Pin Yuan.A closed form solution for constant flux pumping in a well under partial penetration condition[J].Water resources research,2006,42 (5)

[13] Shaw Yang Yang,Yeh, Hund Der.Radial groundwater flow to a finite diameter well in a leaky confined aquifer with a finite - thickness skin[J].Hydrological Processes,2009,23 (23):3382-3390.

[14] Yen Ju Chen,Yeh, Hund Der.Parameter estimation/sensitivity analysis for an aquifer test with skin effect[J].Ground water,2009,47 (2):287-299. 